\section{Social Innovation in Brazilian Social Entrepreneurships: A Proposed Scale for its Classification}

\author{
Edison Quirino D`Amario' \\ Graziella Maria Comini ${ }^{1}$ \\ ${ }^{1}$ University of São Paulo, Faculty of Economics, Administration and Accounting, \\ Department of Administration, São Paulo, Brazil
}

\begin{abstract}
Purpose - Social entrepreneurship and social innovation have attracted particular attention from policy makers, academics, and practitioners since the year 2000. As this area of knowledge is still incipient in the present literature, this study aims to develop and validate a scale to understand how social entrepreneurs identify social innovations generated by their entrepreneurships.
\end{abstract}

Design/methodology/approach - In order to validate the scale, we applied it to 264 social enterprises in the 27 confederative units of Brazil. The statistical techniques used, besides the descriptive analysis of frequencies and central tendency and variability measures, were exploratory and confirmatory factor analysis.

Findings - The results point to a validated scale consisting of 23 items that classify and identify social innovations of the product, organizational, and marketing types, and of incremental, disruptive, and institutional depths.

Originality/value - The contribution to the understanding lies in the fact that the scale may stimulate social entrepreneurs or new entrants to better allocate their resources or their attention to certain types of social innovations in order to achieve better results for their entrepreneurships.

Keywords - Social innovation, scale, social entrepreneurships
Received on

$12 / 12 / 2018$

Approved on

06/20/2019

Responsible editor:

Prof. Dr. João Mauricio Gama

Boaventura

Evaluation process:

Double Blind Review 


\section{Introduction}

Few social phenomena have attracted as much attention since the 2000s as the pursuit to reduce world poverty and improve world health. This is not only a result of economic prosperity but also of governmental and/or non-governmental organizations' actions, which aim to rescue people living in conditions of social vulnerability and insert them into society, ensuring their rights and a dignified life. The term that has been used to refer to these organizations is "social enterprises" (Austin, Stevenson, \& Wei-Skillern, 2006; Fischer \& Comini, 2012).

Social entrepreneurship, commonly defined as an entrepreneurial activity with a social purpose, has been presented as an important economic phenomenon that has been observed on a global scale (Austin, Stevenson, \& WeiSkillern, 2006; Mair \& Marti, 2006). Unlike traditional entrepreneurship, which offers numerous resources for measuring its impact, social entrepreneurship is typically measured qualitatively. In this sense, some studies, for example the one by Comini (2016), have been conducted qualitatively with the purpose of analyzing social innovation generated by social enterprises.

Comini (2016) argues that competition continues to increase, and as a result, all areas should engage more strongly in innovation, both social as well as technological. But, unlike technological innovation, on which there are many studies in the literature, the research on social innovation is still incipient, especially concerning quantitative studies.

Van der Have and Rubalcaba (2016) carried out a bibliometric analysis to trace the content, scope, and relatively short history of modern social innovation research across disciplines. Their analysis suggests that "the social innovation field is grounded in four distinct intellectual communities arising through a somewhat organized diffusion process: community psychology; creativity research; social and societal challenges; and local development" (Van de Have \& Rubalcaba, 2016, p. 1).

In this paper we analyze social innovation as social and societal challenges; nevertheless, this study also highlights social entrepreneurship and social innovation as a field of study that still requires better exploration and articulation, as pointed out by Tiskoski, Rosolen, and Comini (2013). The literature has often highlighted that social entrepreneurship and social innovation are tools that meet social challenges and contribute to sustainable development (Pozzebon \& Fontenelle, 2018). Thus, researchers and practitioners have paid special attention to and have presented a growing interest in these areas. As Van der Have and Rubalcaba (2016) stated, the interest in social innovation in the area of management and entrepreneurship is very recent in the literature.

Nevertheless, in a systematic literature review regarding quantitative studies to better understand social innovations generated by social entrepreneurships, we noticed a lack of studies aimed at identifying social innovations adopted by social entrepreneurs. Thus, with the objective of contributing to the literature on social innovation and social entrepreneurship, this paper aims to develop and validate a scale to classify perceived social innovations used by social entrepreneurs.

Although social innovation has been studied by several authors, no study was observed in the literature that verifies the types, depths, and coverage of social innovations used or developed by social entrepreneurs. Most of the studies concerning scales to assess social innovation or social entrepreneurship involve evaluating value creation in social entrepreneurships, as can be noted in the study by Christlieb (2012), who developed a quantitative study on social entrepreneurs to assess the value creation achieved by entrepreneurships. Bulut, Eren, and Halac (2013) also developed a valid and reliable instrument to assess social innovations, but at the individual level. This gap in the literature was what motivated us to develop a scale that could assess the types and depths of social innovation 
from the perspective of the social entrepreneur. The contribution to the understanding lies in the fact that it may stimulate social entrepreneurs or new entrants to better allocate their resources or their attention to certain types of social innovations in order to achieve better results for their entrepreneurships.

The novelty of our study is that it addresses the challenge of understanding how social entrepreneurs perceive the social innovations that their activities utilize to achieve the aim of obtaining a positive social and/or environmental impact. Understanding how they realize the innovations generated by their activities could set up a new lens that reveals the intention of every entrepreneur concerning the impact generated by social innovations, and it could serve as a guide for future entrepreneurs who wish to engage in some kind of activity, whether for profit or not, to provide a positive social impact through social innovations (Dees, Haas, \& Haas, 1998). Additionally, for academia, the challenge is to deepen the understanding of social innovation practices so that this could contribute to clarifying the concept, because it is still being formed, as can be observed in the studies by Freeman (1987), Johannessen, Oslan, and Lumpkin (2001), and Rieg and Alves (2003).

In this paper, we first present the theoretical background regarding social entrepreneurship and social innovation. Second, we perform a systematic literature review and establish procedures to investigate research that could identify or measure social innovations. Third, we develop the scale using variables from the literature review. Finally, we present the validated scale using a national sample, as well as the limitations and suggestions for future research.

\section{Theoretical Background}

In this section, we present arguments to support social entrepreneurship as a field of study that is growing in the literature, pointing out the relevance that some authors have been giving to it. We also analyze social innovation as a term that comes from traditional innovation, but which still features some misinterpretation in the current literature, and we propose the conceptual model that will be used to analyze the social innovation constructs.

\subsection{Social entrepreneurship}

Despite the growing academic interest in social entrepreneurship, the field still lacks a better conceptual understanding of the economic role and logic of the actions of social entrepreneurship (Santos, 2009). Some research typically defines social entrepreneurs as entrepreneurs with a social mission and considers social entrepreneurship as entrepreneurial activities with social purposes (Dees, Haas, \& Haas, 1998). Therefore, the definition is derived from the integration of these two concepts: "entrepreneurship" and "social."

Some of the most impressive social enterprises are found in developing countries and involve the deployment of new business models that care about human needs (Seelos \& Mair, 2005), such as the provision of low cost cataract surgery to cure visual impairment. However, the phenomenon of social entrepreneurship is also vibrant in developed countries. For example, according to a survey of the Global Entrepreneurship Monitor, 1.2 million people in the United Kingdom (which represents $3.2 \%$ of the working age population) are social entrepreneurs (defined in the survey as people who have been involved in and have performed a social role for less than 42 months). Since the comparable number for traditional entrepreneurship is 6.2\%, these data raise the intriguing possibility that social entrepreneurship may be almost as important as the traditional form (Harding, 2006).

This significant percentage is consistent with the fact that social entrepreneurship has become a construct that has been widely discussed since the beginning of the 2000s, as we can verify in the study by Tiskoski, Rosolen, and Comini (2013). It is also observed that the academic work on the "social entrepreneurship" topic is growing, as is reflected in the numbers of available articles 
in national and international databases, according to a bibliometric study conducted by the authors. This increasing interest in social entrepreneurship is often evidenced by the success stories around the world in various fields (health, education, finance, culture, etc.); the concept has become increasingly evident in commercial markets, academic discourse, and policy-making (Nicholls, 2006).

Concerning its definition, Austin, Stevenson, and Wei-Skillern (2006) point out that social entrepreneurship ranges from a broad to a narrow definition. However, the authors agree that it typically refers to the use of business expertise and market-based skills in the non-profit sector.

Most of the studied cases of social entrepreneurship, although they make use of the market logic to run their businesses, need to adapt to a new way of facing social problems in order to solve them, and make use of social innovations to achieve that goal. The study by Doherty, Haugh, and Lyon (2014) provides a contribution to the understanding of social entrepreneurship by pointing out that it pursues the dual mission of providing both financial sustainability and a social outcome. The authors emphasize that social entrepreneurship does not fit perfectly into the conventional categories of private, public, or non-profit organizations, mainly because it has a social purpose.

Although several authors present definitions of social entrepreneurship, adapting it from the literature on traditional entrepreneurship, its definition is still unclear and imprecise, as pointed out by Groot and Dankbaar (2014), because some authors understand that social entrepreneurship is, by definition, not for profit, but others understand that it can be. The authors offer the example of the internet and Skype. They argue that Skype is a tool that can enable disadvantaged people to be in regular contact with their children or grandchildren and even see them on the computer or phone screen without having to pay expensive telephone calls. In this sense, although the creators of Skype did not have a social intention when they created that tool, it is, per se, a social innovation.
In order to clarify the concept of social entrepreneurship and operationalize the construct, Dwivedi and Weerawardena (2018) offer five dimensions that drive the social enterprise: innovativeness, proactivity, risk management, effectual orientation, and social mission. Additionally, the authors observe a positive influence on social innovation.

In order to better understand social entrepreneurship, the next subchapter reports the concepts of social innovation addressed in the literature.

\subsection{Social innovation}

From the phenomenon of innovation that has been widely discussed in the literature, we can observe an offshoot of its understanding and application that advances within the social scope: social innovations. We can note a growing interest in social innovation among governments, foundations, researchers, and academic institutions around the world. However, despite this interest, we do not find a shared or common concept of social innovation.

Mulgan, Tucker, Rushanara, and Sanders (2007) defined social innovation as new ideas with the purpose of meeting social goals. These new ideas may be, for example, new partnerships, new lifestyles, new products and services, and new processes. In addition, the authors emphasize that there are also organizational social innovations that combine new types of organizations with social purposes and marketing social innovations. Although the authors clearly defined social innovation, we can see that its definition comes from that of business innovation that can be verified in the Oslo Manual (1997), but to which the social character is added. Other authors, such as Maclean, Harvey, and Gordon (2013), agree that social innovation implies new ideas that aim to improve quality of life, provide a better education, and a longer life expectancy; that is, initiatives that promote community well-being and environmental sustainability.

The lack of clarity on the term "social innovation" can be attributed not only to its 
analytical status, but also to its simplistic use as a "buzzword" (Moulaert, MacCallum, \& Hiller, 2013). This lack of consensus among the experts on social innovation can also be explained by the contemporary subject, as verified in a study on meta-synthesis of social innovation conducted by Morais-da-Silva, Takahashi, and Segato (2016).

Besides the lack of clarity or the lack of consensus around the definition of social innovation, most authors agree that unlike business innovations that are driven by competition or profit, social innovation is geared toward social purposes rather than commercial gain (Dawson \& Daniel, 2010). In other words, for these authors, social innovation can be understood as new concepts, strategies, and tools that support vulnerable groups of people with the objective of improving their well-being.

These strategies, as pointed out by Groot and Dankbaar (2014), must survive for a certain period of time to be recognized as social innovations. The authors add that social innovation should have some sort of diffusion to other locations, including other communities, regions, or even other countries.

In a bibliometric study to clarify the concept of social innovation, Pacheco, Santos, and Silva (2018) placed emphasis on its innovative nature, such as the launch of new services or products, the development of new processes, or new forms of association and cooperation agreements that add value to society. In this sense, social innovation therefore adds new solutions to specific situations to generate processes of change and transformation. In the authors' bibliometric study, among the papers that were most cited in the literature, none had the purpose of developing a scale to identify social innovations used by social entrepreneurs.
Regarding social innovation as agreements that add value to society, Phills, Deiglmeier, and Miller (2008) define social in terms of social value, according to which an innovation is truly social only if the balance is tilted toward social value, that is, it benefits society as a whole, instead of one particular value creation, that is, gains for entrepreneurs, investors, and ordinary consumers.

As we can see, the definitions and understanding of social innovation have their roots based in the definition of traditional innovation, observing, of course, their aim of resolving or alleviating the social problems of a group of people or even a community.

\subsection{Conceptualization of constructs}

In order to develop the social innovation constructs, we followed the procedures offered by DeVellis (2012). Based on the literature review, which is explained in the methodological procedures, we defined the conceptual model of social innovation analyzed in this study, as shown in Figure 1.

This proposed conceptual model of social innovation is made up of three dimensions: types, depths, and coverage. The "types" dimension encompasses four first-order constructs, which are product, process, marketing, and organizational; the "depths" dimension encompasses three first-order constructs, which are disruptive, institutional, and incremental; and the "coverage" dimension encompasses four first-order constructs, which are local, regional, national, and global. 


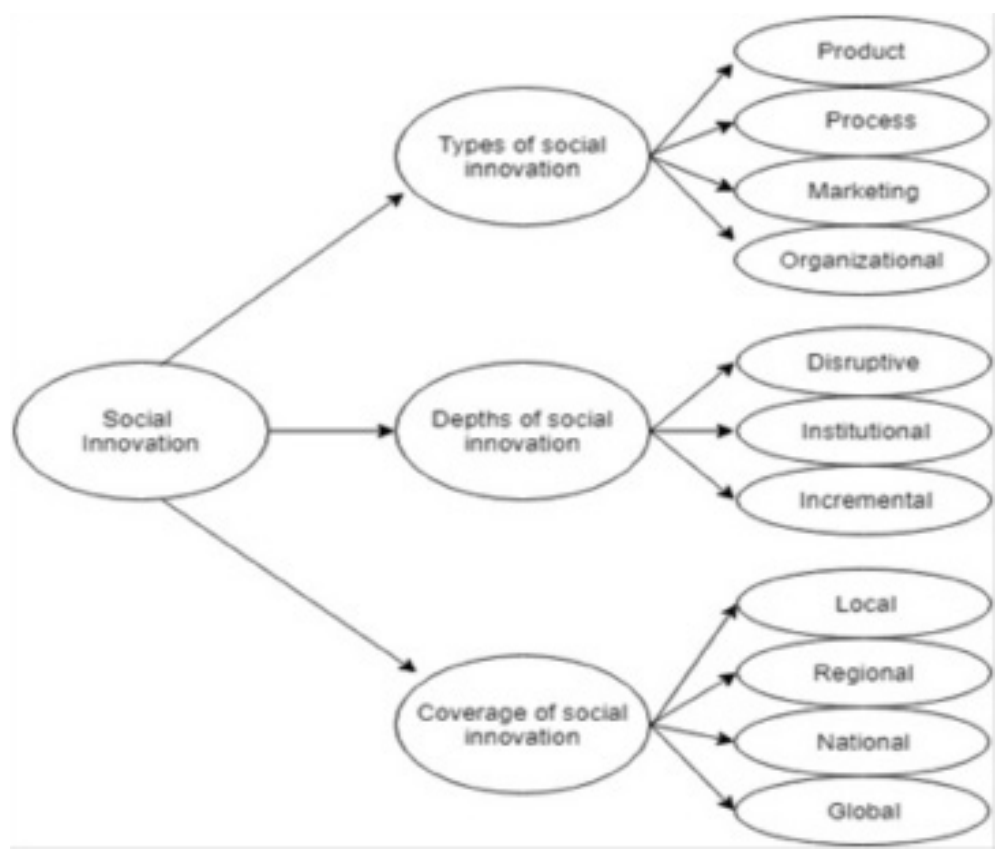

Figure 1. Conceptual model

Because it is a subject that is still under construction and, consequently, does not yet present a consensus on the specific meaning, as pointed out by Pol and Ville (2009), in order to elaborate the dimensions and types of social innovation we decided to use the classification of traditional innovation offered by the Oslo Manual (1997), adapting it for a social purpose as presented in Table 1.

Table 1

\section{Types of social innovations}

\begin{tabular}{lll}
\hline Type & Definition & Source \\
\hline Product & $\begin{array}{l}\text { Introduction of a new good or service or a significantly improved one in terms of its characteristics } \\
\text { or uses. It includes significant improvements in technical specifications, components and materials, } \\
\text { incorporated software, user friendliness, or other functional characteristics to meet social goals; }\end{array}$ & $\begin{array}{l}\text { Adapted from } \\
\text { the Oslo } \\
\text { Manual (1997) }\end{array}$ \\
\hline Process & $\begin{array}{l}\text { Implementation of a new or significantly improved method of production or distribution. It } \\
\text { includes significant changes in techniques, equipment, and/or software to meet social goals; }\end{array}$ & $\begin{array}{l}\text { Adapted from } \\
\text { the Oslo } \\
\text { Manual (1997) }\end{array}$ \\
\hline Marketing & $\begin{array}{l}\text { Implementation of a new marketing method with significant changes in the product design or in its } \\
\text { packaging, in the product positioning, in its promotion, or in its price setting to meet social goals; }\end{array}$ & $\begin{array}{l}\text { Adapted from } \\
\text { the Oslo }\end{array}$ \\
& & Manual (1997) \\
\hline Organizational & $\begin{array}{l}\text { Implementation of a new organizational method in the company's business practices, in } \\
\text { organizing its workplace, or in its external relations to meet social goals. }\end{array}$ & $\begin{array}{l}\text { Adapted from } \\
\text { the Oslo }\end{array}$ \\
& & Manual (1997) \\
\hline
\end{tabular}

Innovations involve changes, but not all forms of changes can be qualified as innovation. Only qualitative changes that deconstruct practices and common knowledge in a particular area can be called innovations. In this sense, innovations can also be classified according to their magnitude. Social innovations occur at multiple levels based on the focus of expertise, which can be of a disruptive, incremental, and institutional nature (Nicholls \& Murdock, 2012), as presented in Table 2. 
Table 2

\section{Characteristics of social innovations - Depth}

\begin{tabular}{|c|c|c|}
\hline Depth & Definition & Source \\
\hline Disruptive & $\begin{array}{l}\text { The theoretical contribution regarding disruptive social } \\
\text { innovation describes it as a process by which a product } \\
\text { or service that was initially historically accessible only to } \\
\text { consumers with high purchasing power becomes accessible to } \\
\text { consumers with lower purchasing power }\end{array}$ & $\begin{array}{l}\text { Christensen, MacDonald, Altman, and Palmer } \\
\text { (2018); Moulaert et al. (2013); Nicholls and } \\
\text { Murdock (2012); Goldenberg (2004); Anderson, } \\
\text { Curtis, and Wittig (2014); Bruin and Stangl (2013) }\end{array}$ \\
\hline Institutional & $\begin{array}{l}\text { It is noted that social innovations that focus on the } \\
\text { reconfiguration of existing economic and social structures, } \\
\text { usually by repositioning new technologies more directed } \\
\text { towards social rather than economic goals, must be regarded } \\
\text { as institutional social innovations }\end{array}$ & $\begin{array}{l}\text { Nicholls and Murdock (2012); Bruin and Stangl } \\
\text { (2013); Moulaert et al. (2013); Groot and Dankbaar } \\
\text { (2014) }\end{array}$ \\
\hline Incremental & $\begin{array}{l}\text { Incremental social innovations can be understood as the } \\
\text { development of new forms of working partnerships with } \\
\text { coordination and alignment of initiatives and which are } \\
\text { directed toward a common goal and aim to mitigate social } \\
\text { problems }\end{array}$ & $\begin{array}{l}\text { Christensen, MacDonald, Altman, and Palmer } \\
\text { (2018); Bruin and Stangl (2013); Moulaert et al. } \\
\text { (2013) }\end{array}$ \\
\hline
\end{tabular}

As the intention of this study is to propose a scale to classify social innovation in terms of types, depths, and coverage, we decided to use the coverage classification used by Comini (2016), which consists of observing the occurrence of social innovations from a local to a global perspective, as presented in Table 3.

Table 3

\section{The coverage of social innovations}

\begin{tabular}{|c|c|c|}
\hline Coverage & Definition & Source \\
\hline Local & $\begin{array}{l}\text { Local innovations address social and/or environmental problems of a particular community or } \\
\text { town; }\end{array}$ & Comini (2016) \\
\hline Regional & $\begin{array}{l}\text { Regional social innovations serve a region or some regions (South, North, etc.) and may also } \\
\text { reach some states; }\end{array}$ & Comini (2016) \\
\hline National & Social innovations with national coverage extend all over a country; & Comini (2016) \\
\hline Global & Global social innovations serve several countries & Comini (2016) \\
\hline
\end{tabular}

The types, characteristics, and depths of innovations and social innovations presented in Tables 1, 2, and 3 were verified or adapted from the literature and the objective was to support the conceptual model and elaborate the items that were used by the proposed scale of this study and explained in the methodological procedures.

\section{Methodological Procedures}

Before proceeding to the development of the scale, we reviewed the literature to verify if there were studies that offer scales to classify or measure social innovations. The stages proposed by Petticrew and Roberts (2006) to conduct the literature review were followed. We used the Scopus platform for the search. This database was chosen because it is supported by several software tools besides allowing the observation of important data, such as summaries, dates, authors, institutions, and countries.

Additionally, we used the Web of Science search tool in order to verify if other studies could perhaps be found. However, after the search, using the same tool filters as the ones used in Scopus, no new study was found. As search filters, we used the following keywords and their derivations, which 
were observed in the literature: Social Innovation Measurement (Nicholls, 2009), Social Impact Measurement (Nicholls, 2009), Measuring Social Impact (Bloom, 2012), and Social Impact Scale (Bulut, Eren, \& Halac, 2013). We also filtered for articles found in social sciences, business and economics, and finally, for ones in English, Spanish, and Portuguese. As the studies on social innovation are practically new in the literature, we did not opt for a timeframe.

Initially, the results of the search, without the use of the filters mentioned, pointed to 179 articles with the Social Innovation Measurement theme. After using the filters, four articles were found. The results indicated that some studies that sought to measure or classify the social innovation of social entrepreneurships did not do it with the purpose of identifying the type of innovation, depth, and coverage, as intended in this study.

In the second stage of the search, we used related terms to obtain a greater scope. The main search term in this second stage was Measuring Social Innovation. The search results indicated that there were 717 articles. After the application of the filters (only articles on management, business, economics, and social issues), nine articles were found, but no article had the same objective as this study.

In third form of search, the main term used was Social Impact Measurement. After the use of the filters mentioned, five studies were obtained. In the fourth and last form of search, we used the term Social Innovation Scale. After using the aforementioned filters, only one article was found. It is important to mention that in the searches performed, no article was found with the same purpose as this study.

After conducting all four stages of the search, the only studies that measured social innovations were the ones by Bulut, Eren, and Halac (2013), who developed an instrument with the intention of measuring social innovation, but only at the individual level, and the one by Christlieb (2012), who developed a quantitative instrument to assess value creation among social entrepreneurs. Therefore, we did not find in the systematic research any quantitative study with the same objective as this one, and so we proceeded to the development of the scale.

\subsection{Developing the scale - initial procedures}

In order to develop the scale, we followed the procedures found in the literature for the development of items, consisting of seven steps (DeVellis, 2012):

Step 1: What we wanted to verify in this study was the occurrence of social innovation in social entrepreneurships, identify their geographical coverage, and classify their types and depths.

Step 2: For the first list of items in the scale to be drawn up, we based this on the literature on innovation, social innovation, social entrepreneurship, and value creation. The quality of the items was not considered in the first list; they still had to be reassessed before their examination by experts, and so we developed 53 items based exclusively on the literature.

Step 3: The chosen scale type that most suited the goals of the research was a Likert-type ordinal scale because it enables respondents to indicate their degree of agreement regarding the items. We opted for a six-point scale ( $1=$ totally agree and $6=$ strongly disagree).

Step 4: After preparing potential items to compose the final scale, they were submitted for analysis by experts. They had to indicate whether the item had a high, moderate, or low capacity to measure the construct of interest. Additionally, we asked the experts to clarify, justify, or even suggest changes to each item.

Step 5: In this step, after careful assessment it was decided which items should be included in the scale.

Step 6: The items were evaluated concerning their individual performance so that they could compose the final scale.

Step 7: After evaluating the items selected, we had to decide whether to maintain, increase, 
or reduce the number of items in the final scale, taking into account the reliability of the scale.

Pre-test: After following the steps proposed by DeVellis (2012), we included the research instrument on the Survey Monkey platform and asked six social entrepreneurs to answer the questionnaire and send, by e-mail, their considerations regarding their understanding of the variables and any other perceptions they felt were relevant in order to improve the instrument.

\subsection{Sampling plan}

The sampling plan was developed in five steps. Steps 1 to 4 refer to the content validation, and the step 5 refers to the psychometric validation.

1st step: 5 master and doctoral students who were researching social innovation;

2nd step: 20 master and doctoral students who were attending the "Social Business and Entrepreneurship" course at the University of São Paulo.

3rd step: $7 \mathrm{PhD}$ professors of social innovation.

4th step: 6 social entrepreneurs (pre-test).

5th step: 264 social entrepreneurs.

The sample universe of the 5 th step was composed of 1195 social organizations. This mapping was done by researchers of the Brasil27 Project, which aims to strengthen social entrepreneurship culture and support existing ventures. The project studied cases of social or nonprofit organizations in the 27 states of Brazil. The objective of the project was to present a complete framework of the reality of social entrepreneurship. There were six criteria used by the project researchers to consider entrepreneurships as social ones: 1) not being a corporate social responsibility initiative; 2) having a social and environmental mission; 3) having a social impact; 4) the social impact caused in the value chain should support it financially; 5) deriving at least $50 \%$ of its revenue from the sale of products/services, or else having the prospect of becoming financially sustainable (operating indeterminately without the need for donations); 6) being formalized for at least one year. To obtain this sample, we conducted the study using an online questionnaire and asked for the participation of the 1195 social organizations via e-mail.

After following the first four steps in the sampling plan, from the 53 items initially developed, we obtained a 39-item scale to classify social innovation initiatives. The items in this scale intended to assess core aspects of social innovation as felt by the participants. We included items to assess the type (process, product, institutional, marketing, and organizational), depth (incremental, disruptive, and institutional), and geographical coverage of social innovations. In the 3rd step, the professors of social innovation suggested we move the geographical coverage variable to the demographic variables. We also included items to distinguish between the types of organizations (associations, foundations, cooperatives, and enterprises); the sex of the founder; the consumers they serve; and the size of the organization, using the number of employees for this.

\subsection{Scale validation}

In order to validate the scale, after conducting the 5th step, we used SPSS V.22 to carry out the statistical analysis. We used multivariate data analysis, which comprises a set of techniques that analyze multiple variables in a single relationship or a set of relationships simultaneously (Hair, Black, Babin, \& Anderson, 2011). To this end, after analyzing the lost values, extreme values, relative frequency, mean, standard deviation, and coefficient of variation, we used multivariate analysis techniques: exploratory factor analysis (EFA) and confirmatory factor analysis (CFA).

The variables were measured on a numeric scale and for this reason they are liable for analysis using central tendency and variability measures. This initial investigation is important because it provides specific and synthetic information on each variable in the study. 
The median is a central tendency measure that identifies the center of gravity of the data distribution of a variable. As measures of variability, we used the standard deviation and the coefficient of variation. The standard deviation is a measure that indicates the distance of the data around the middle, while the coefficient of variation offers a better interpretation to indicate whether the data are dispersed around the middle (Fávero, Belfiore, Silva, \& Chan, 2009).

It is evidenced that for most variables, the coefficient of variation (CV) was below 0.5 , indicating low variability, and that the average is a good measure to synthesize the data of each variable.

\subsection{Exploratory factor analysis (EFA)}

EFA, as an exploratory and interdependent technique, is commonly used to find an optimal structure of factors, considering each factor or construct as consisting of a group of observable or manifested variables that are correlated with each other. However, with the use of a dataset and confirmatory techniques, EFA fulfills the sole purpose of reducing and selecting variables that meet the assumptions of the technique (Maroco, 2014). This objective is clarified by stating that EFA can allow the study of interrelationships between a large number of variables in order to condense the information contained in each group (Fávero et al., 2009).

The reduction is based on the analysis of the correlation matrix, which seeks a combination of simplicity and explanatory power of the phenomenon through grouping dimensions and total variance respectively. To perform this process, the assumptions are assessed, which allows us to select the variables that best fit into a dimension. The use of four assumptions is suggested: anti-image, commonality, factorial load, and cross-load. If a variable does not meet the 4 assumptions, the variable is excluded from the analysis and will not be part of the next steps, i.e. the confirmatory techniques (Fávero et al., 2009; Hair et al., 2011). Anti-image is the same as partial correlations after the factor analysis and consists of a measure that explains the degree to which the factors explain each other. The measure is evaluated for each item and must be greater than 0.5. Commonality is the portion of variance that a variable shares with all the other variables included in the factor model; it is the most important factor for the selection of variables, since those variables that do not reach the cut-off point, set at 0.5 , are summarily excluded from the analysis. When a variable does not reach 0.5 in commonality, it means that the portion of shared variance for the variable is less than random (Hair et al., 2011). The factorial load is defined as the correlation between the variables that make up the dimension and the dimension itself. The factorial load must be at least 0.4 . The cross-load uses the measure of factorials loads, consisting of the incidence of high factorial loads in two or more dimensions. A variable must have a high factorial load in only one dimension.

The EFA was used in this research in sequenced steps, starting with the matrix of correlations among the variables tested. In the global analysis of the model, the Bartlett and the KMO (Keiser-Meyer-Olkin) tests were used to verify the presence of correlations between the variables and the adequacy of the sample complexity of the model, respectively. The values found were satisfactory. In the Bartlett test, the significance was below 0.05 , resulting in 0.000 , and indicating that the correlations between the variables were not null. The KMO value found was 0.902 , indicating great balance between the number of variables and the size of the sample (Hair et al., 2011).

Factor analysis consists of sequenced steps. First we chose a method to extract the dimensions. For this, principal component analysis (PCA) is commonly used. Another decision to make is in relation to the rotation of the dimensions. Orthogonal rotation, obeying a $90^{\circ}$ angle on a plane in $\mathrm{N}$ dimensions, offers better interpretability, and decreases the incidence of cross-loading. In this method, the correlations between dimensions are arbitrated at zero. It is 
suggested by the literature (Maroco, 2014) to follow the steps of analysis using orthogonal rotation and, finally, to check the factorial solution found by the oblique variant, which accepts the correlations between dimensions. If there is similarity between both analyses, it shows that the correlations between the factors do not interfere significantly in the factorial model. After those decisions were taken, the calculations of the assumptions were made, and in each round of review, the assumptions were assessed according to their reference values and rules of decision.

After conducting the EFA, eight variables were excluded from the scale because they did not meet the assumptions. After finishing the EFA, we conducted the confirmatory factor analysis.

\subsection{Confirmatory factor analysis (CFA)}

The first part of the analysis sought to validate a theoretical model. When we finished the EFA, as an exploratory step, CFA was conducted in order to validate the empirical model. The first step consists of verifying the assumptions of the CFA with the purpose of deciding whether to use the multivariate technique. First, the model was tested and then we carried out the factorial, convergent, and discriminant validity tests.

The conditions evaluated in the CFA for covariances follow the recommendations expressed in the literature (Hair et al., 2011; Maroco, 2014). The assumptions must be met in order to avoid type 1 and 2 measurement errors. The first and basic assumption to evaluate is the linearity of the model; the model must be linear to use a linear technique, such as CFA. When imported to AMOS (a statistical software package for structural equation modeling), the software confirmed the linearity of the model calculating the parameters to be estimated.

Another related construct design of the model is the appointment of at least three clear variables for each construct; the literature indicates deleting the whole construct when it is formed of only 1 or 2 variables (Hair et al., 2011; Maroco, 2014). The social construct, proposed by variables 1 to 4 , had to be excluded because it had variables 3 and 4 deleted in the EFA for violating one or more assumptions.

Another assumption that was also answered when designing the research tool was whether to use a scale with a strong measure, i.e., a metric scale with 5 points or more.

One of the assumptions relates to the high correlation between the manifest variables. A way to avoid multicollinearity is by performing the VIF (variance inflation factor) test. The test was performed in the previous step in SPSS and confirmed the low influence of multicollinearity, even if it was present. The final assumption verified in AMOS, after importing the data, was the detection of multivariate normality in the variables. This test is performed by the third-and fourth-order measures, which are respectively the asymmetry (sk) and kurtosis (ku). The sk and ku results for the manifest variables were evaluated and no variable violated the reference values.

Thus, the conditions for the use of the CFA, including the variables evaluated, did not violate the assumptions. Then, an analysis was conducted to generate parameter estimates. As in EFA, the variables can be deleted through the results found in the CFA. The initial model was formed of 7 constructs and 29 variables. The model was designed in AMOS and the maximum likelihood (ML) method was used, the same method used in the last step of the EFA. We evaluated the commonality and factorial loads to assign the reference values, which define 0.5 or more for commonality, and a factorial load of 0.6 or higher (Maroco, 2014). The violation of the reference values was accepted by the investigator, who sought parsimony. The modification indices were also evaluated to identify possible similarities between errors of the variables. A corrective measure is to include a correlation between the errors. In the first round, the goodness-offit indices of the model were: $\chi^{2}(356)=\chi^{2}$ $1106.440 / \mathrm{df}=3.108 ; \mathrm{CFI}=0.813 ; \mathrm{TLI}=0.787$; $\mathrm{NFI}=0.750, \mathrm{MECVI}=4.885$, and RMSEA $=$ 0.090 pclose $=0.000$. The $\chi^{2} / \mathrm{df}$ index is defined 
as the quotient of the chi-square test of the degrees of freedom. It must be less than 5 , indicating a good fit, even without any improvement of the factorial model (Maroco, 2014). The CFI, TLI, and NFI obtained were close to 0.8 , indicating a good fit, and the RMSEA of between 0.05 and 0.1 indicates a great fit. The MECVI obtained indicates that the model is complex.

Concerning the factorial loads, most of them were close to or exceeded 0.7. The commonalities obtained were close to 0.5 or above. However, there are variables that were not close to the minimum factorial load and commonality measures accepted, as is the case of variable 27 , which presented a commonality of 0.17 and factorial load of 0.41 . In relation to the contents of modification, a limit of 30 was arbitrarily set, being an index that also does not present reference values in the literature. The defined limit depends on the complexity of the model, seeking to balance simplicity and completeness. We found high rates of change between the errors of variables 24 and 27, with a MI of 44, this being the largest MI found between the errors of the variables. Another MI above 30 was found in variables 10 and 17 , with $\mathrm{MI}=36$. It was decided to correlate the errors of variables with a high MI and exclude variable 27.

After these modifications, the model showed a remarkable improvement, with an increase of the factorial loads and commonalities of the variables, in addition to an improvement in the goodness-of-fit indices: $\chi^{2}(328)=\chi^{2} 904.401 / \mathrm{df}$ $=2.757$; $\mathrm{CFI}=0.850 ; \mathrm{TLI}=0.827$; NFI $=0.786$; MECVI $=4.105 ;$ RMSEA $=0.082 ;$ and pclose $=$ 0.000 . Although the model had improved, variable 11, the Disruptive Depth construct, presented a low commonality of 0.33 . Thus, the variable was removed from the model for a new test.
After deleting the variable, the model showed further improvement, through weaker than the previous one. The global fit measures in this round were: $\chi^{2}(302)=\chi^{2} 822.975 /$ $\mathrm{df}=2.725$; $\mathrm{CFI}=0.859$; $\mathrm{TLI}=0.837$; $\mathrm{NFI}=$ 0.797; $\mathrm{MECVI}=3.776$; RMSEA $=0.081$; and pclose $=0.000$. Observing the factorial loads, we still verified variables that did not reach the minimum reference value for the parameter. In the Organizational Type construct, variable 38 presented a factorial load of 0.57 and commonality of 0.32 , and so it was excluded from the analysis.

The model was tested again in search of the best global fit and we still found a slight improvement, but with global index values very close to those found earlier. However, in the Process Type construct, variable 24 presented a low commonality of 0.22 . As this construct featured only 3 variables, we decided to exclude the whole construct, for violating the assumption of having 3 variables in each one. After doing that, the model was tested again and it was verified that there was a significant improvement in global fit. With 6 constructs, the model showed lower complexity, as seen in the improvement in the MECVI index. The other global indices also showed appropriate measures: $\chi^{2}(214)=\chi^{2}$ $611.387 / \mathrm{df}=2.857$; $\mathrm{CFI}=0.870$; $\mathrm{TLI}=0.846$; $\mathrm{NFI}=0.815 ; \mathrm{MECVI}=2.843 ; \mathrm{RMSEA}=0.084$; and pclose $=0.000$.

After all the rounds reported, the factorial model presented variables that approach or pass the minimum commonality and factorial load values required. Thus, the final factorial model consisted of 23 variables, as presented in Table 4, excluding variables $11,38,23,24,27$, and 25 . Variables 1 and 2 were deleted even before the CFA, for violating the assumption of having at least three variables per construct. 
Table 4

Final factorial model results

\begin{tabular}{|c|c|c|c|c|c|c|c|}
\hline Relationships & & & $\begin{array}{c}\text { Non standardized } \\
\text { results }\end{array}$ & S.E & C.R. & $\mathbf{P}$ & $\begin{array}{c}\text { Standardized } \\
\text { results }\end{array}$ \\
\hline Var. 6 & $<--$ & PI & 1,000 & & & & 0,721 \\
\hline Var. 8 & $<--$ & PI & 1,163 & 0,103 & 11,249 & $* * *$ & 0,839 \\
\hline Var. 9 & $<--$ & PI & 0,933 & 0,096 & 9,735 & $* * *$ & 0,673 \\
\hline Var. 15 & $<--$ & PD & 1,000 & & & & 0,583 \\
\hline Var. 14 & $<--$ & $\mathrm{PD}$ & 1,264 & 0,135 & 9,335 & $* * *$ & 0,792 \\
\hline Var. 13 & $<--$ & PD & 1,176 & 0,129 & 9,131 & $* * *$ & 0,763 \\
\hline Var. 12 & $<--$ & $\mathrm{PD}$ & 1,059 & 0,127 & 8,368 & $* * *$ & 0,666 \\
\hline Var. 10 & $<--$ & $\mathrm{PD}$ & 1,012 & 0,127 & 7,988 & $* * *$ & 0,619 \\
\hline Var. 17 & $<--$ & TI & 1,000 & & & & 0,719 \\
\hline Var. 18 & $<--$ & TI & 0,926 & 0,097 & 9,532 & $* * *$ & 0,637 \\
\hline Var. 19 & $<--$ & TI & 0,986 & 0,097 & 10,130 & $* * *$ & 0,678 \\
\hline Var. 20 & $<--$ & TI & 1,051 & 0,098 & 10,770 & $* * *$ & 0,724 \\
\hline Var. 26 & $<--$ & Prod & 1,000 & & & & 0,749 \\
\hline Var. 28 & $<--$ & Prod & 1,113 & 0,087 & 12,810 & $* * *$ & 0,834 \\
\hline Var. 29 & $<--$ & Prod & 1,029 & 0,086 & 11,967 & $* * *$ & 0,771 \\
\hline Var. 30 & $<--$ & $\mathrm{TM}$ & 1,000 & & & & 0,734 \\
\hline Var. 31 & $<--$ & $\mathrm{TM}$ & 1,136 & 0,089 & 12,815 & $* * *$ & 0,834 \\
\hline Var. 32 & $<--$ & $\mathrm{TM}$ & 1,002 & 0,088 & 11,372 & $* * *$ & 0,736 \\
\hline Var. 33 & $<--$ & $\mathrm{TM}$ & 1,108 & 0,088 & 12,544 & $* * *$ & 0,814 \\
\hline Var. 39 & $<--$ & Org & 1,000 & & & & 0,662 \\
\hline Var. 37 & $<--$ & Org & 1,315 & 0,131 & 10,010 & $* * *$ & 0,785 \\
\hline Var. 36 & $<--$ & Org & 1,048 & 0,113 & 9,252 & $* * *$ & 0,697 \\
\hline Var. 35 & $<--$ & Org & 1,218 & 0,128 & 9,541 & $* * *$ & 0,727 \\
\hline
\end{tabular}

The standard error (SE) is the estimated error; it reflects the accuracy with which each parameter was estimated. Very high or very small SEs reflect a poor model because they hamper the determination of the parameters. The factorial model generated presents low SEs, indicating a high level of accuracy in the estimation. CR is critical ratio, consisting of the ratio between the estimated parameters for the errors. This test follows the normal distribution: a two-tailed 99\% confidence level. The p-value of the CR was close to zero, and consequently it rejects the null hypothesis, showing that the estimates were different from zero.

With the final model obtained, the next step was the validation of the theoretical model.
First, the suggestion is to check the factorial validity (Hair et al., 2011; Maroco, 2014). Variable 15 is the only variable that does not meet the minimum of 0.6 , obtaining 0.583 . However, variables with values close to the minimum are accepted, if the model achieves a good fit even with that variable.

Other types of validity are convergent and discriminant. Convergent validity is obtained by reaching minimum values of composite reliability (CR) and average variance extracted (AVE). For convergent validity, the $\mathrm{CR}$ must be greater than 0.7 and the AVE greater than 0.5. The convergent and discriminant validity results are presented in Table 5. 
Table 5

Convergent and discriminant validity results of the CFA

\begin{tabular}{|c|c|c|c|c|c|c|c|c|}
\hline & EVA & DP & PI & TI & Prod & Org & MT & RC \\
\hline Disruptive Depth (DP) & 0,50 & 0,5 & & & & & & 0,833 \\
\hline Incremental Depth (IP) & 0,55 & 0,41 & 0,55 & & & & & 0,758 \\
\hline Institutional Type (IT) & 0,50 & 0,43 & 0,36 & 0,50 & & & & 0.785 \\
\hline Product Type (Prod) & 0,62 & 0,28 & 0,35 & 0,46 & 0,62 & & & 0,833 \\
\hline Organizational Type (Org) & 0,52 & 0,19 & 0,05 & 0,40 & 0,26 & 0,52 & & 0,810 \\
\hline Marketing Type (MT) & 0,61 & 0,06 & 0,43 & 0,23 & 0,46 & 0,19 & 0,61 & 0,862 \\
\hline
\end{tabular}

Note. The table presents the average variance extracted and the composite reliability.

Is it evidenced that the convergent validity is met, since the AVE for each construct is greater than or equal to 0.5 , and the $\mathrm{CR}$ is greater than 0.7 in all constructs. Discriminant validity under the criterion of the literature (Fornell \& Larker, 1981) is also satisfied, since each AVE is larger than the correlations between the squared constructs. Therefore, the model is validated in terms of its consistency and repeatability.

\section{Results}

\subsection{Descriptive analysis of the sample}

In order to demonstrate those that were part of the sample for the validation of the scale, in this topic the profile of the researched organizations is presented. According to the results, the majority of the organizations are associations. The types and percentages of the organizations are: associations (61.74\%), foundations $(7.20 \%)$, cooperatives $(4.55 \%)$, and enterprises (26.52\%).

Regarding the sex of the founder, $59.09 \%$ are men and $40.91 \%$ are women. Most organizations serve the consumers of a city or community (43.18\%), however there is a good representation of organizations with greater coverage: one state or region (23.48\%); a country (20.45\%); and a number of countries (12.88\%).
Concerning the size of the organizations, $58.33 \%$ are micro organizations (up to 19 employees), $35.23 \%$ are small organizations (from 20 to 99 employees), 6.06\% are mediumsized organizations (100 to 499 employees), and only $0.38 \%$ of the organizations surveyed are considered large (over 500 employees).

Regarding the age of the organizations, it is observed that most of them were founded in the last 30 years, although we found some organizations founded before that and one that has been in operation since 1896 .

The majority of the organizations surveyed, around 40\%, are headquartered in the State of São Paulo, followed by Rio de Janeiro and Minas Gerais. It is also noted that at least one organization represents each federative state of Brazil.

\subsection{Final scale validated}

After the entire methodological process for the development of the scale and the descriptive analyses of the sample, we present the final validated scale in Table 6 . We emphasize that of the 59 items initially developed, 23 remained, which, in turn, evaluate the product, marketing, and organizational types of social innovation; and the incremental, disruptive, and institutional depths. Regarding the geographic coverage, we decided not to include this in the final scale because each researcher could choose to use it or not. 


\section{Table 6}

\section{Validated scale}

\section{Incremental social innovation variables}

1-Our products/services already existed, but we have improved them and reduced the costs so that people who are in situations of social vulnerability can have access to them.

2-We have developed new products/services that are cheaper than the ones that already existed and that serve socially vulnerable populations.

3-We have improved products and/or services that already existed to reduce the environmental impact and/or to serve people in situations of social vulnerability.

\section{Disruptive social innovation variables}

4-Our new products/services enable social and/or politic participation by people who are in situations of social vulnerability.

5-Our new products/services transform the lives of people in situations of vulnerability.

6-Our new products/services meet a challenge, creating equality, social justice, and empowerment.

7-Our products/services are new alternatives offered to individuals and organizations as a means to achieve social change in their communities.

8-Our new products/services have changed the market structure to serve people in situations of social vulnerability.

Institutional social innovation variables

9-Our new products/services promote changes in social relations by increasing the level of participation of socially vulnerable groups.

10-We perform updates in products/services that lead to the inclusion of historically excluded groups.

11-Our new products/services focus on the reconfiguration of existing social and economic structures with new technologies that are more targeted at minorities who are in situations of social vulnerability.

12-Our new products/services rewrite and create new markets to serve people who are in situations of social vulnerability.

\section{Product social innovation variables}

13-Our products/services have innovative functional features that suit the demands and/or consumer profile of people in situations of social vulnerability.

14-Our products/services have changes that do not alter their function or intended use, but best suit the demands of consumers in situation of social vulnerability.

15-Our products/services have changes in their characteristics that are perceived as valuable by consumers, especially those in situations of social vulnerability.

\section{Marketing social innovation variables}

16-We use marketing to generate a new conception of the product and/or service in order to facilitate its use by people in situations of social vulnerability, and/or cause less environmental impact.

17-We use a new method of sales promotion or pricing, in order to enable consumption by people in situations of social vulnerability, and/or cause less environmental impact.

18-Our products/services have a new design that fits the profile of consumers in situations of social vulnerability and/or where the environmental impact is minimal.

19-We intend to increase the sales volume through changes in the positioning of our products/services in order to make them accessible to consumers in situations of social vulnerability.

\section{Organizational social innovation variables}

20-Our organization achieves its social and/or environmental objectives by utilizing new methods of partnerships with other organizations to learn new ways of working.

21-We seek to acquire knowledge and interact with other organizations to achieve our social and/or environmental objectives.

22-Our organization employs new methods of interaction with other companies to share knowledge and achieve its social and/or environmental objectives.

23-Our products/services are part of new initiatives and partnerships which aim to reduce social and environmental problems. 


\section{Discussion and Conclusions}

It is important to highlight that the main purpose of this study was not to perform an "X-ray" of social innovations generated by social entrepreneurships, but to develop and validate a scale that could be used by researchers to identify social innovation in terms of the types, depths, and coverage used or developed by social entrepreneurs.

The development of the scale was supported by several content (DeVellis, 2012; Tilden \& Nelson, 1992) and psychometric (Fávero et al. 2009; Hair et al, 2011; Maroco, 2014) procedures to ensure its validity, such as exploratory and confirmatory factor analyses, observing all their assumptions to validate the items. Nevertheless, as this is the first study of this type, we recommend future studies to validate the measure presented in this one with other samples. We also recommend future studies pay special attention concerning process social innovation, which could not be validated in this sample. This finding is consistent with that of Comini (2016), who also faced difficulties in identifying process innovations in the 27 social enterprises surveyed.

We hope this scale can be used by researchers who wish to deepen the understanding of social innovations adopted by social entrepreneurs with different samples and contribute to the growth of the knowledge in this area, which has been highlighted in the literature.

\section{References}

Anderson, T., Curtis, A., \& Wittig C. (2014). Definition and theory in social innovation. Krems: Danube University Krems.

Austin, J., Stevenson, H., \& Wei-Skillern, J. (2006). Social and commercial entrepreneurship: Same, different, or both? Entrepreneurship theory: and practice, 30(1), 1-22.

Bloom, P. N. (2012). Scaling your social venture: Becoming an impact entrepreneur. Hampshire: Palgrave Macmillan.
Bulut, C., Eren, H. Halac, \& D. S. (2013). Social innovation and psychometric analysis. ProcediaSocial and Behavioral Sciences, 82, 122-130.

Bruin, A., \& Stangl, L. M. (2013). The "Social Innovation Continuum" in Auckland Council. Social Innovation in Auckland, 13-68.

Christensen, C. M., MacDonald, R. Altman, E. J., \& Palmer, J. E. (2018). Disruptive innovation: An intellectual history and directions for future research. Journal of Management Studies, 55(7), 1043-1078.

Comini, G. M. (2016). Negócios sociais e inovação social: Um retrato de experiências brasileiras. (Doctoral Thesis) Faculdade de Economia, Administração e Contabilidade da Universidade de São Paulo, São Paulo, Brasil. Retrieved from https://edisciplinas.usp. br/pluginfile.php/4100966/mod_resource/ content/0/Tese_livre_docencia_final_Graziella_ Comini.pdf

Christlieb, J. (2012). Measuring social value creation: A quantitative study among social entrepreneurs (Master thesis). Universiteit Twente, Enschede, Nederland. Retrieved from https:// essay.utwente.nl/62631/1/MSc_J_Christlieb.pdf

Dawson, P., \& Daniel, L. (2010). Understanding social innovation: A provisional framework. International Journal of Technology Management, 51(1), 9-21.

Dees, J. G., Haas, M., \& Haas, P. (1998). The Meaning of "Social Entrepreneurship". CASE. https://centers.fuqua.duke.edu/case/knowledge_ items/the-meaning-of-social-entrepreneurship/

DeVellis, R. F. (2012). Scale development: Theory and applications (3rd ed.). Los Angeles: Sage.

Dwivedi, A., \& Weerawardena, J. (2018). Conceptualizing and operationalizing the social entrepreneurship construct. Journal of Business Research, Elsevier, 86, 32-40. 
Doherty, B., Haugh, H., \& Lyon, F. (2014). Social enterprises as hybrid organizations: A review and research agenda. International Journal of Management Reviews, 16(4), 417-436.

Fávero, L. P., Belfiore, P., Silva, F. L., \& Chan, B. L. (2009). Análise de dados: Modelagem multivariada para tomada de decisôes. Rio de Janeiro: Elsevier.

Fischer, R. M., \& Comini G. (2012). Sustainable development: From responsibility to entrepreneurship. Revista de Administração da USP, 47(3), 363-369.

Fornell, C., \& Larker, D. F. (1981). Evaluating structural equation models with unobservable variables and measurement error. Journal of Marketing Research, 18(1), 39-50.

Freeman, C. 1987. Technology policy and economic performance: Lessons from Japan. London: Frances Pinter.

Goldenberg, M. (2004). Social innovation in Canada how the non-profit sector serves Canadians and how it can serve them better. Canadian Policy Research Networks Inc. Project (CPRN).

Groot, A., \& Dankbaar, B. (2014). Does social innovation require social entrepreneurship? Technology Innovation Management Review, 4(12).

Hair, J. F., Black, W. C., Babin, B. J., \& Anderson, R. E. (2011). Multivariate data analysis: A global perspective. New Jersey: Pearson Prentice Hall.

Harding, R. (2006). Social entrepreneurship monitor. London: Global Entrepreneurship Monitor.

Johannessen, J. A., Oslan, B., \& Lumpkin, G. T. (2001). Innovation as newness: What is new, how new, and new to whom? European Journal of Innovation Management, 4(1), 20-31.
Maclean, M., Harvey, C., \& Gordon, J. (2013). Social innovation, social entrepreneurship and the practice of contemporary entrepreneurial philanthropy. International Small Business Journal, 31(7), 747-763.

Mair, J., \& Marti, I. (2006). Social entrepreneurship research: A source of explanation, prediction and delight. Journal of World Business, 41(1), 36-44.

Morais-da-Silva, R. L. M., Takahashi, A. R. W., \& Segatto, A. P. (2016). Scaling up social innovation: a meta-synthesis. RAM - Revista de Administração da Mackenzie, 17(6) 134-163.

Maroco, J. (2014). Análise estatística com o SPSS Statistics (6 ed.). Lisboa: Ediçôes Sílabo.

Moulaert, F., MacCallum, D., \& Hiller, J. (2013). Social innovation: Intuition, precept, concept, theory and practice. In F. Moulaert, D., MacCallum, A. Mehmood, \& A. Hamdouch (Eds.), The international handbook on social innovation: Collective action, social learning and transdisciplinary research (pp. 13-24). Cheltenham, UK, and Northampton, MA, USA: Edward Elgar.

Mulgan, G., Tucker, S., Rushanara, A., \& Sanders, B. (2007). Social innovation: What it is, why it matters and how it can be accelerated. Oxford: Said Business School.

Nicholls, A. (2006). Introduction. In A. Nicholls (Ed.), Social entrepreneurship: New models of sustainable social change (pp. 1-35). Oxford: Oxford University Press.

Nicholls, A., (2009). We do good things, don't we?: Blended value accounting in social entrepreneurship. Accounting, Organizations and Society, 34(6-7), 755-769.

Nicholls, A., \& Murdock, A. (2012). Social innovation: Blurring boundaries to reconfigure markets. London: Palgrave Macmillan. 
Oslo Manual (1997). Diretrizes para coleta e interpretação de dados sobre inovação. Retrieved from http://www.finep.gov.br/images/apoio-efinanciamento/manualoslo.pdf.

Pacheco, A. S. V., Santos, M. J., \& Silva, K. V. (2018). Social innovation: What do we know and do not know about it. International Journal of Innovation and Learning, 24(3), 301- 326.

Petticrew, M., \& Roberts, H. (2006). Systematic reviews in the social sciences: A practical guide. Oxford: Blackwell Publishing, Ltd.

Phills, J. R., Jr., Deiglmeier K., \& Miller D. T. (2008). Rediscovering social innovation. Stanford Social Innovation Review, 34-43.

Pol, E., \& Ville, S. (2009). Social innovation: Buzz word or enduring term? The Journal of Social Economics, 38(6), 878-885.

Pozzebon, M., \& Fontenelle, I. A. (2018). Fostering the post-development debate: The Latin American concept of tecnologia social. Third World Quarterly, 39(9), 1750-1769.

Rieg, D. L., \& Alves, A. G., Filho (2003). Esforço tecnológico e desempenho inovador das empresas do setor médico-hospitalar localizadas em São
Carlos, SP. Gestão e Produção, 10(3), 293-310. http://dx.doi.org/10.159

Santos, F. M. (2009). A positive theory of social entrepreneurship. France: Fontainebleau.

Schumpeter, J. A. (1912). The theory of economic development. New Jersey: Transaction Publishers.

Seelos, C., \& Mair, J. (2005). Social entrepreneurship: Creating new business models to serve the poor. Business Horizons, 48(3), 241-246.

Tilden, V. P., Nelson, C. A., \& May, B. A. (1990). Use of qualitative methods to enhance content validity. Nursing Research, 39(3), 172-175. https:// doi.org/10.1097/00006199-199005000-00015

Tiskoski, G. P., Rosolen, T., \& Comini, G. M. (2013). Empreendedorismo social e negócios sociais: Um estudo bibliométrico da produção nacional e internacional. Encontro da Anpad, Rio de Janeiro, RJ, Brasil, 37. Retrieved from http://www.anpad.org.br/admin/pdf/2013_ EnANPAD_APB1365.pdf

Van der Have, R. P., \& Rubalcaba, L. (2016). Social innovation research: An emerging area of innovation studies? Research Policy, 45(9), 1923-1935. 


\section{Authors:}

1. Edison Quirino D`Amario, PhD, University of São Paulo, Faculty of Economics, Administration and Accounting, Department of Administration, São Paulo, Brazil.

E-mail: edamario@uol.com.br

\section{ORCID}

(iD) 0000-0003-4297-2281

2. Graziella Maria Comini, PhD, University of São Paulo, Faculty of Economics, Administration and Accounting, Department of Administration, São Paulo, Brazil.

Email: gcomini@usp.br

ORCID

(iD) 0000-0002-3474-2833

\section{Contribution of each author}

\begin{tabular}{lcc}
\hline Contribution & Edison D`Amario & Graziella Comini \\
\hline 1. Definition of research problem & $\sqrt{ }$ & $\sqrt{ }$ \\
2. Development of hypotheses or research questions (empirical studies) & $\sqrt{ }$ & $\sqrt{ }$ \\
3. Development of theoretical propositions (theoretical Work) & $\sqrt{ }$ & $\sqrt{ }$ \\
4. Theoretical foundation/ Literature review & $\sqrt{ }$ \\
5. Definition of methodological procedures & $\sqrt{ }$ & $\sqrt{ }$ \\
6. Data collection & $\sqrt{ }$ \\
7. Statistical analysis & $\sqrt{ }$ & $\sqrt{ }$ \\
8. Analysis and interpretation of data & $\sqrt{ }$ & $\sqrt{ }$ \\
9. Critical revision of the manuscript & $\sqrt{ }$ \\
10. Manuscript Writing & $\sqrt{ }$ \\
11. Other (please specify which) & & $\sqrt{ }$ \\
\end{tabular}

